\title{
Investigations on lightweight concrete prepared by combinations of rubber particles and expanded glass aggregate
}

\author{
Suman Kumar Adhikary ${ }^{1}$, Žymantas Rudžionis ${ }^{2}$ \\ Civil Engineering and Architecture, Kaunas University of Technology, Kaunas, Lithuania

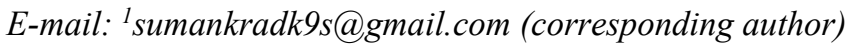

\begin{abstract}
Lightweight concrete is a very useful building material used in the construction sector for providing better insulation and lower energy consumption. Properties of lightweight aggregate, water-cement ratio, and other additives strongly affect the concrete strength, thermal properties, and workability. This paper investigates the behavior of lightweight concrete using rubber particles as fine aggregate, replaced by the expanded glass lightweight aggregate in the concrete mixture. In the concrete mixture expanded glass aggregate is replaced by rubber particles by $5 \%, 10 \%, 20 \%$, $30 \%, 40 \%$, and $50 \%$ by mass. Concrete workability, density, compressive strength, flexural strength, water absorption tests were examined. Workability and density were increasing by increasing rubber particles replacement percentages in the concrete mixture. On the other hand, compressive strength and flexural strength were decreasing by higher percentages of rubber particles replacement. Strength properties of rubberized concrete can be balanced by the proper utilization of binding materials in the concrete. Rubberized concrete can be used in the construction sector efficiently as partial replacement of lightweight aggregate in the concrete mixture.
\end{abstract}

Keywords: rubberised concrete, rubber particles, lightweight concrete, expanded glass aggregate concrete.

\section{Introduction}

Due to rapid development in technology and growing population, the demands of vehicles are increasing every year which directly increase the demand for rubber tires. The number of wastes tires is increasing continuously resulting in severe environmental pollution (Su, Yang, Ling, Ghataora, \& Dirar, 2015). Every year almost 1000 million waste tires are generated worldwide, and it is expected by 2030 that the numbers of wastes tires can reach up to 1200 million (Segre \& Joekes, 2000). Disposal of rubber tires now become a big problem globally and landfilling method becomes the cheapest and easiest method. To protect the environment effectively reusing the waste rubbers become an important issue. Rubberized concrete is environmentally friendly concrete produced by the addition of rubber particles/ powder in the concrete mixture. The higher volume of rubber particles/ powder decreases the strength properties of concrete. From the past few years, many researchers are working on the rubberized concrete to analyze the behavior of concrete under the addition of rubber (Ramdani, Guettala, Benmalek, \& Aguiar, 2019; Sugapriya \& Ramkrishnan, 2018; Liu, Wang, Jiao, \& Sha, 2016; Akinyele, Salim, \& Kupolati, 2016). Blessen et al. showed in his study replacing natural sand by $0 \%$ to $20 \%$ of crumb rubber that abrasion resistance and water absorption properties of rubberized concrete was improved compromising the little amount of mechanical and durability properties (Thomas \& Gupta, 2016). Similarly, Herrandez et al. study the dynamic characteristics of rubberized concrete (Hernández-Olivares, Barluenga, Bollati, \& Witoszek, (2002) and it has been found that rubberized concrete has possible advantages in term of reducing the vibration and impact effect due to its elastic properties. In addition, Thomas et al. found in his investigation that rubberized concrete has significant resistance towards aggressive environments like carbonation, acid attack, chloride ion penetration and freeze-thaw resistance (Thomas, Gupta, \& Panicker, 2016). Dong et al. and Al-Tayed et al. showed in their study that increasing volume of crumb rubbers in concrete decreases the compressive strength of concrete (Al-Tayeb, Abu Bakar, Akil, \& Ismail, 2013; Dong, Huang, \& Shu, 2013). Rubberized concrete is highly environmentally friendly and sustainable and can be used in various prospects. There are various recycled materials are also used to produce lightweight concrete like expanded glass aggregates, recycled polystyrene, recycled plastics and waste Perlite (Pichór, Kamiński, Szołdra, \& Frąc, 2019; Chung et al., 2017; Gregorova, Ledererova, \& Stefunkova, 2017; Adhikary, Rudzionis, \& Zubrus, 2019; Gerges, Issa, \& Fawaz, 2018). However, this study investigates the mechanical properties of lightweight concrete prepared by combinations of rubber particles and expanded glass aggregates, and the findings are presented. 


\section{Materials and methods}

EN 450-1:2012 (British Standards Institution, 2012) standard satisfied fly ash and EN 197-1:2011 (British Standard Institution, 2011) standard satisfied ordinary Portland cement of grade CEM I 42.5R (Rocket cement M-600, AB Cementa, Stockholm) was used in the study. Two different sizes of lightweight expanded glass aggregates $2.5 / 1.25 \mathrm{~mm}$ and 1.25/0.63 mm were used was used in the study. Rubber particles (crushed tires) were used as a replacement of expanded glass aggregates to prepare different type of concrete samples. The size of the rubber particles was 500 microns to $1 \mathrm{~mm}$ with the average bulk density of $297 \mathrm{~kg} / \mathrm{m}^{3}$. Masterglenium SKY 8700 polycarboxylate ether polymers based superplasticizer and MasterMatrix SDC 100 stabilizer used to achieve better results in terms of getting good flowability and to reduce segregation. Figure 1 shows the used expanded glass aggregate and rubber particles. The properties of expanded glass aggregates like thermal conductivity, bulk density, and specific density were calculated which can be seen in Table 1 .
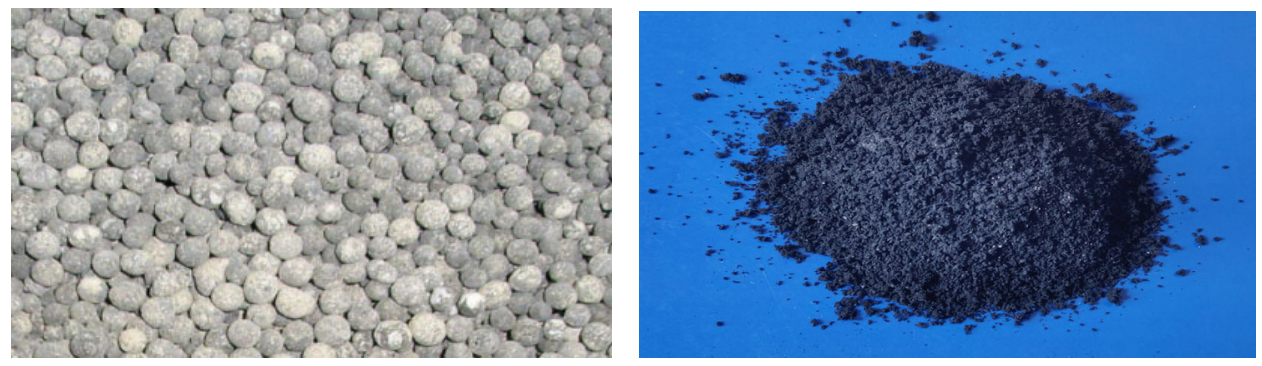

Figure 1. Expanded glass aggregate and rubber particles

Table 1. Properties of expanded glass aggregates

\begin{tabular}{|l|c|c|c|}
\hline \multicolumn{1}{|c|}{ Designation } & \multirow{2}{*}{ Standard } & \multicolumn{2}{c|}{ Expanded glass aggregate size } \\
\cline { 3 - 4 } & & $2.5 / 1.25 \mathrm{~mm}$ & $1.25 / 0.63$ \\
\hline Bulk density in $\mathrm{kg} / \mathrm{m}^{3}$ & EN 1097-3 & 166.13 & 213.66 \\
\hline Thermal conductivity in W/(m-k) & EN 12939:2002 & $0.065-0.070$ & $0.065-0.070$ \\
\hline $\begin{array}{l}\text { Water absorption \% by mass (absorption \% after } \\
24 \text { hours submerged in water) }\end{array}$ & EN 1097-6:2002 & 20 & 20 \\
\hline Specific density & & & 2.3 \\
\hline pH value & & $9-11$ & $9-11$ \\
\hline Softening point (approximate) & & $700^{\circ} \mathrm{C} / 1300^{\circ} \mathrm{F}$ & $700^{\circ} \mathrm{C} / 1300^{\circ} \mathrm{F}$ \\
\hline
\end{tabular}

Seven different types of concrete samples were prepared to investigate the concrete mechanical and rheological properties under the replacement of expanded glass aggregates by rubber particles. During the preparation of concrete samples, the mass of mixing compositions like cement, fly ash, stabilizer, superplasticizer, and water was kept constant for all samples. The rubber particles were replaced by the mass of expanded glass aggregates. Rubber particles were smaller in size than expanded glass aggregates and have higher bulk density. When we replace the rubber particles by mass of expanded glass aggregates the total mass of the mixture remains constant, but the volume of the mixture decreases by increasing replacement of rubber particles. The volume of mixing compositions of samples also increases by increasing the rubber particles replacement. The mixing proportion of the concrete samples were shown in Table 2 .

Table 2. The mixing proportion of concrete samples, Materials for $1 \mathrm{~m}^{3}$ of Concrete

\begin{tabular}{|c|c|c|c|c|c|c|c|c|}
\hline $\begin{array}{c}\text { Sample } \\
\text { type }\end{array}$ & Cement & $\begin{array}{c}\text { Fly } \\
\text { ash }\end{array}$ & $\begin{array}{c}\text { Expanded glass, } \\
(2.5 / 1.25 \mathrm{~mm}+1.25 / 0.63 \mathrm{~mm})\end{array}$ & $\begin{array}{c}\text { Crushed } \\
\text { Rubber }\end{array}$ & $\begin{array}{c}\text { \% of rubber } \\
\text { by mass }\end{array}$ & Water & $\begin{array}{c}\text { Superplas- } \\
\text { ticizer }\end{array}$ & Stabilizer \\
\hline S-1 & 608.2 & 202.7 & $61.8+61.8$ & 0 & $0 \%$ & 334.7 & 12.15 & 2.68 \\
\hline S-2 & 636.1 & 212 & $61.4+61.4$ & 6.4 & $5 \%$ & 350 & 12.7 & 2.80 \\
\hline S-3 & 645.1 & 215 & $59+59$ & 13.1 & $10 \%$ & 355 & 12.9 & 2.83 \\
\hline S-4 & 650.3 & 216.7 & $52.9+52.9$ & 26.4 & $20 \%$ & 357.8 & 12.9 & 2.86 \\
\hline S-5 & 670.7 & 223.5 & $47.7+47.7$ & 40.8 & $30 \%$ & 369.1 & 13.4 & 2.95 \\
\hline S-6 & 687.3 & 229 & $41.9+41.9$ & 55.9 & $40 \%$ & 378.2 & 13.73 & 3.02 \\
\hline S-7 & 710.1 & 236.8 & $36.1+36.1$ & 72.2 & $50 \%$ & 391 & 14.2 & 3.12 \\
\hline
\end{tabular}


It has been found from the previous study that the presence of higher volume of rubber in the concrete mixture decreases the strength properties of concrete. So, in this study by increasing the quantity of rubber particles binding materials volume also increased to balance the strength properties of concrete. All the procedures were done very carefully to prepare the fresh concrete. After preparing the fresh concrete immediately flow table test was performed to determine the consistency of fresh concrete. Concrete samples were molded to the size of $16.04 \times 4.0 \times 4.0 \mathrm{~cm}$ for the compressive strength and flexural strength test. Each type of concrete specimen density was measured in the fresh state and kept for the hardening process for 24 hours in room temperature. After the hardening process, all the samples were kept immerge in water till $28^{\text {th }}$ day.

\section{Results and discussion}

\section{Flow table test}

Flow table test was carried out according to EN 12350-5:2009 (German National Standard, 2009) standard. Three times flow table test was performed for each type of concrete samples and average spread taken as a result. From the study, it has been found that flow value was increasing with the replacement volume of rubber particles. Expanded glass aggregates were replaced by rubber particles by mass. So, the gap between aggregates was increasing by increasing the quantity of rubber particle in the concrete, because the sizes of rubber particles were too small compared to lightweight expanded glass aggregates. Because of the size differences volume of cement and fly ash paste also increasing by the increasing of rubber particles replacement which helps to increase the flow value. Flow values of concrete samples are shown in Figure 2.

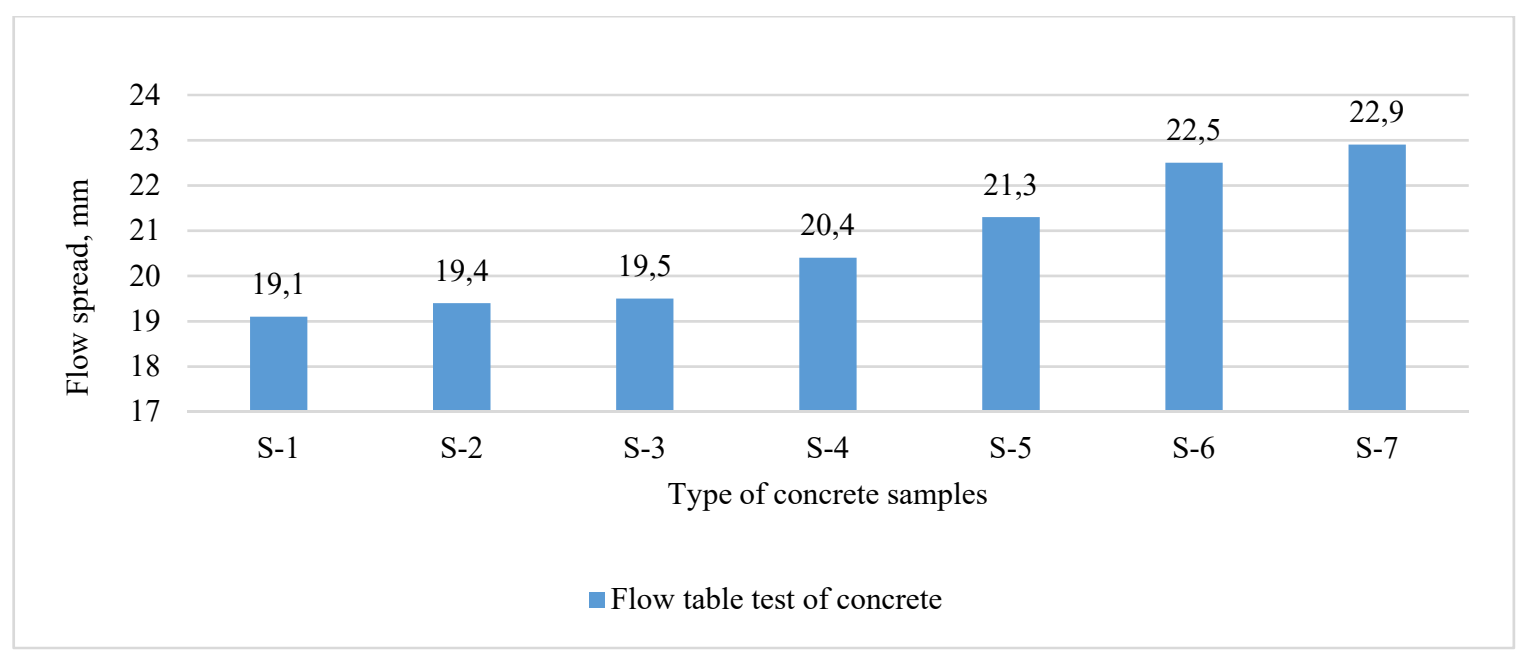

Figure 2. Flow table test of concrete samples

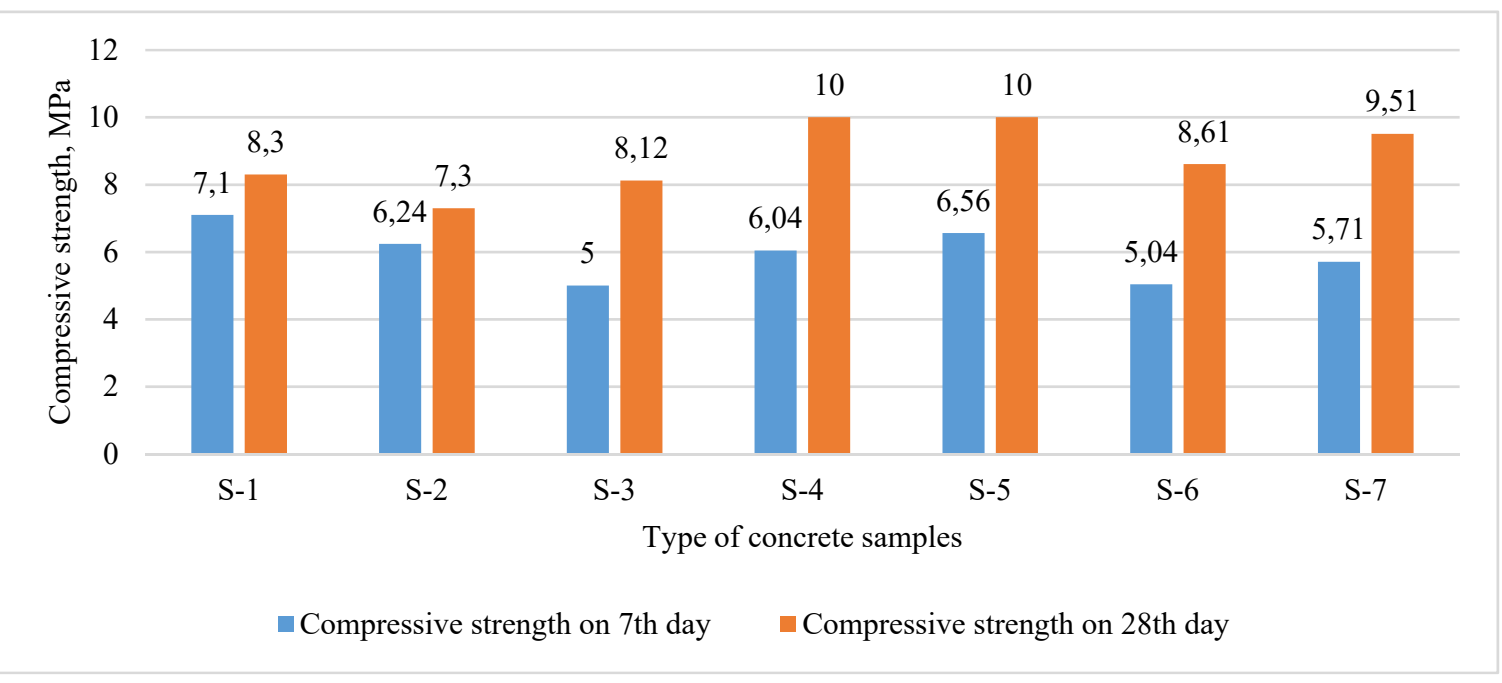

Figure 3. Compressive strength of concrete samples 


\section{Compressive and flexural strength}

Compressive strength and flexural strength test were carried on the $7^{\text {th }}$ and $28^{\text {th }}$ day of curing process satisfying EN 196-1:2016 (British Standard Institution, 2016) standard. For each type of concrete specimens, three tests were done, and the average value taken as a result. It has been found from the study that compressive strength and flexural strength of concrete samples were greatly influenced by the addition of rubber particles and increasing volume of mixing compositions. From Figure 3, it can be understood compressive strength of concrete sample S-2, and S-3 were decreasing when expanded glass aggregates were replaced by rubber particles by $5 \%$ and $10 \%$. Sample S-4 and S-5 achieve higher compressive strength among all type of concrete samples and again it starts decreasing by increasing of rubber particles replacement. Previous studies showed compressive strength of concrete generally decrease when the rubber particles added to the concrete (Al-Tayeb et al., 2013; Dong et al., 2013). But in this study compressive strength doesn't decrease because the quantity of binding materials in the concrete samples was increasing when replacement of expanded glass aggregate was increased. For sample S-2 to sample S-7 expanded glass aggregates were replaced $5 \%$ to $50 \%$ by mass. The density and surface area of expanded glass aggregate and rubber particles was different. Rubber particles density was higher, and the particle size was lesser than the expanded glass aggregates. So, when the volume of replacement of expanded glass aggregates was increasing, the binding materials paste was also increasing in the concrete sample. The gap between the aggregates was increasing and the binding material paste was taking the place which increases the density and strength of concrete. Flexural strength test was carried out on $7^{\text {th }}$ and $28^{\text {th }}$ day of the curing process and almost similar phenomena were observed like compressive strength test. Flexural strength of the concrete sample was decreasing to $20 \%$ replacement of expanded glass aggregates by rubber particles and again it starts increasing because of extra binding material pate in the concrete samples which result increasing of strength properties and density. Figure 4 shows the flexural strength of each type of concrete samples.

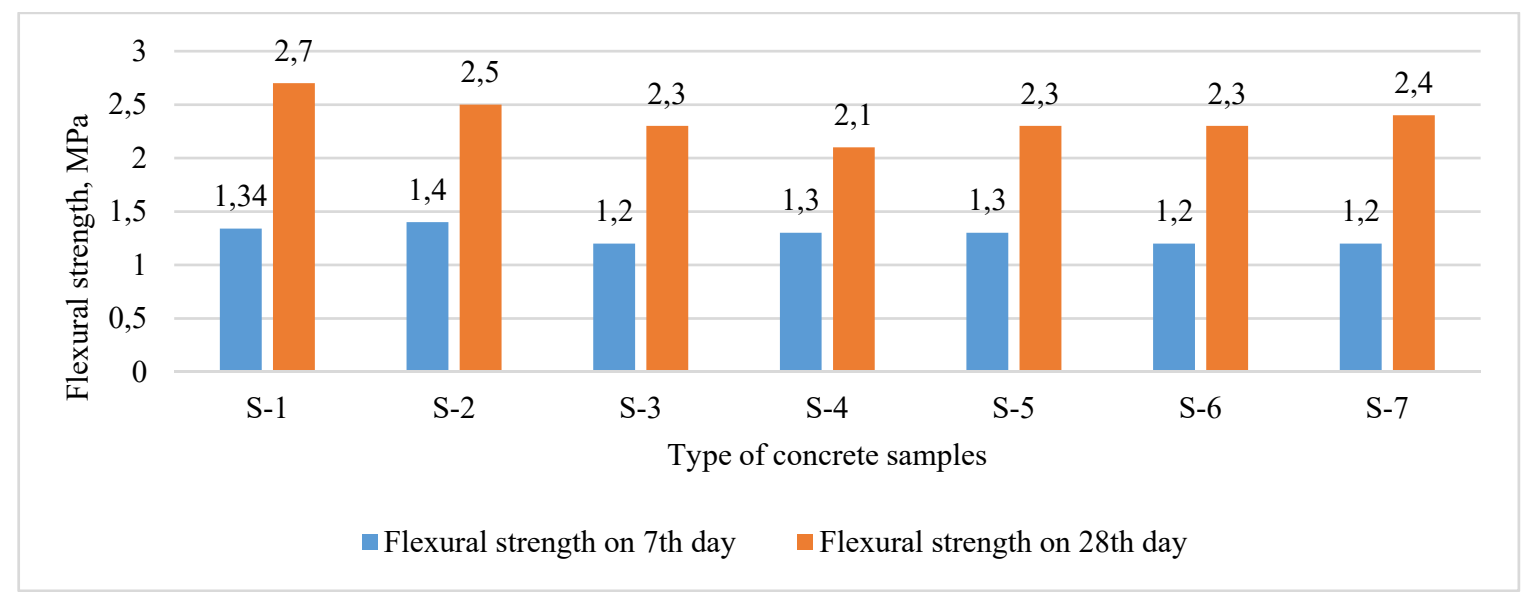

Figure 4. Flexural strength of concrete samples

\section{Density of concrete}

The density of the concrete samples was calculated by the very accurate weighing machine. All the concrete samples density was calculated in four stages. The density of fresh concrete was calculated in the fresh state and on the $7^{\text {th }}$ and 28th day of curing process density of the concrete samples was again calculated. On the $7^{\text {th }}$ and $28^{\text {th }}$ day water immersed concrete samples were taken out and immediately wet concrete samples density was calculated. After that, all the concrete samples were kept in the oven to calculate the dry density of concrete samples. Sample S-1 had the lowest density among the all-concrete samples in the fresh and dry state. The density of all concrete samples was increasing by the increasing replacement quantity of expanded glass by rubber particles. The density of concrete samples increases because with the increasing quantity of rubber particles the volumetric composition of the mixtures was also increased which leads to increase the density of concrete samples. Figure 5 shows the density of each type of concrete samples.

\section{Water absorption}

Water absorption test of concrete samples was carried out on the $7^{\text {th }}$ and 28 th day of the curing process. The concrete samples mass was measured on the fresh state after the molding process, and on the $7^{\text {th }}$ and $28^{\text {th }}$ day water immersed concrete samples were taken out and mass of each concrete samples were measured. The difference of mass of concrete samples was calculated and it has been found that water absorption of concrete samples was higher on $28^{\text {th }}$ day than the $7^{\text {th }}$ day of the curing process. Figure 6 shows the result of water absorption test of concrete samples. It has been found from the study that the volume of expanded glass and rubber particles has great influence on the water absorption properties of concrete. After 30\% replacement of expanded glass aggregates by rubber particles the water absorption properties of concrete increased. 


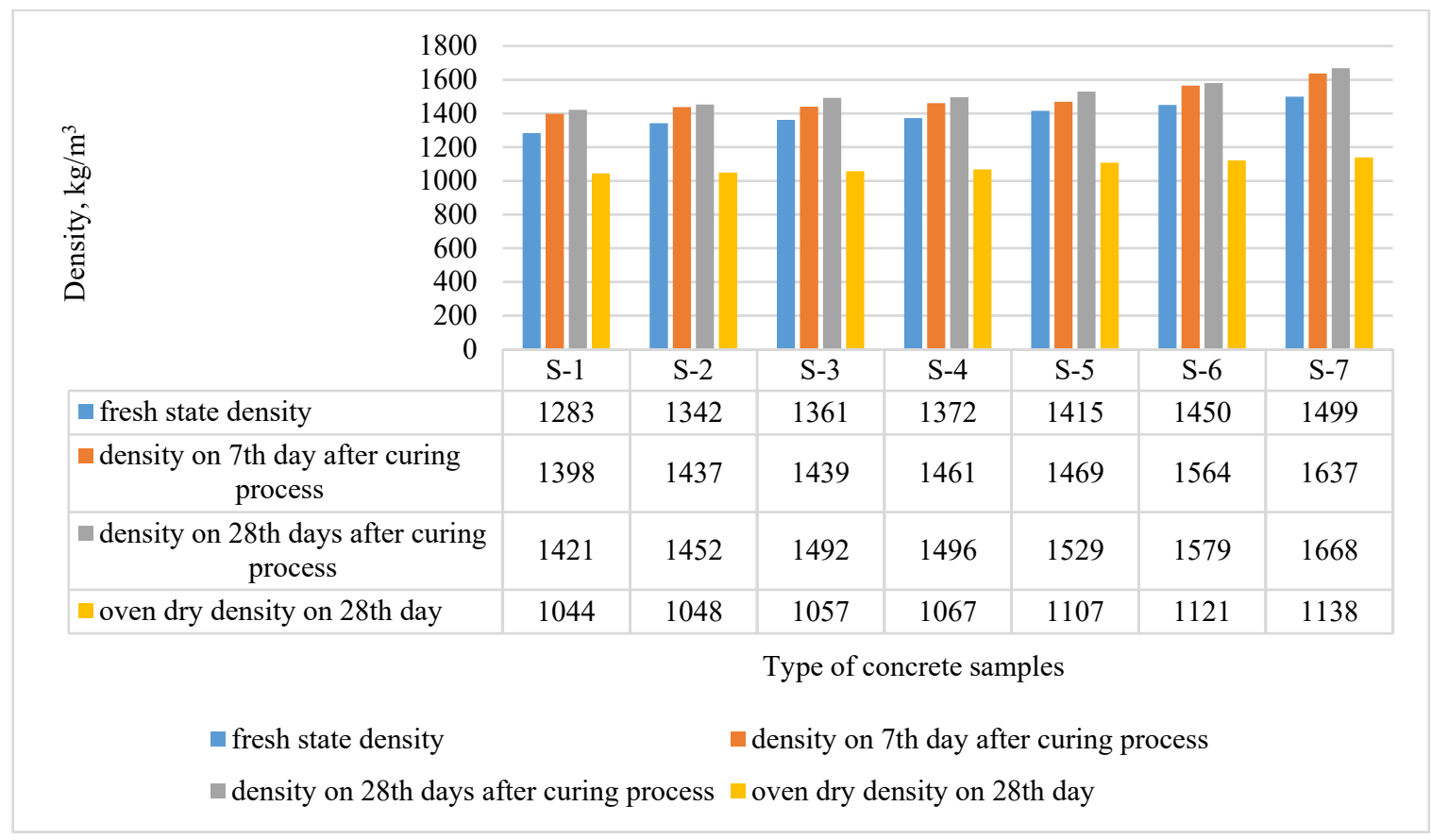

Figure 5. Density of concrete samples

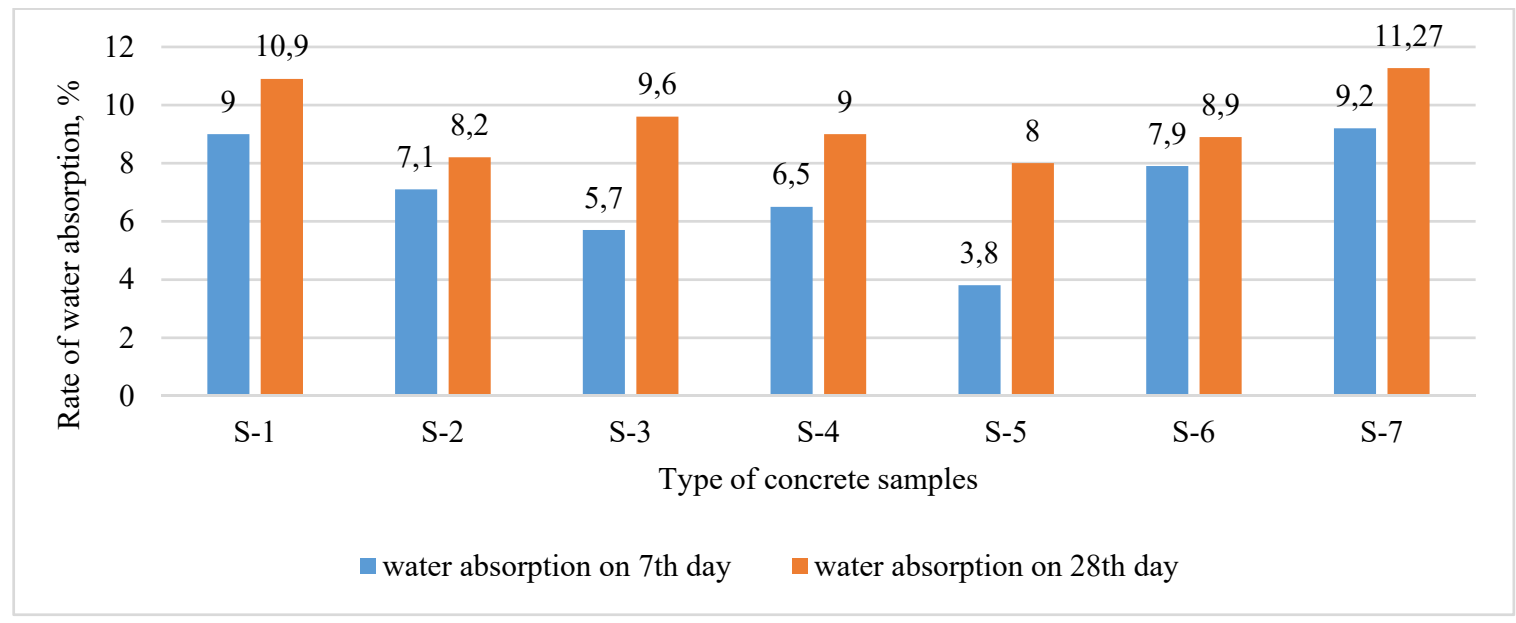

Figure 6. Water absorption of concrete samples

\section{Conclusions}

From the study carried out on the replacing of lightweight expanded glass aggregate by rubber particles in the lightweight rubberized concrete, it can be concluded that-Presence of rubber particles decreases the compressive and flexural strength of concrete, but strength properties of concrete can be increased by allowing more cement paste in the concrete mixture. This study showed concrete samples achieves higher compressive strength by replacing $30 \%$ to $40 \%$ lightweight expanded glass aggregates by rubber particles and flexural strength of concrete was decreasing by the increasing of the quantity of rubber particles. In this study, the volume of binding materials was increased by increasing the quantity of rubber particles to balance the strength properties of concrete samples. Although concrete strength properties can be increased by proper addition of silica fume and other materials without increasing the volume of binding materials. It has been found from the study that compressive strength can be balanced by the addition of higher volume of binding materials in rubberized concrete. Higher volume of binding materials also increases the density of concrete. 


\section{References}

Adhikary, S. K., Rudzionis, Z., \& Zubrus, M. (2019). Investigations of the influence of polystyrene foamed granules on the properties of lightweight concrete. Journal of Applied Engineering Sciences, 9(1), 19-24. https://doi.org/10.2478/jaes-2019-0002

Akinyele, J. O., Salim, R. W., \& Kupolati, W. K. (2016). Production of lightweight concrete from waste tire rubber crumb. Engineering Structures and Technologies, 8(3), 108-116. https://doi.org/10.3846/2029882X.2016.1209727

Al-Tayeb, M. M., Abu Bakar, B. H., Akil, H. M., \& Ismail, H. (2013). Performance of rubberized and hybrid rubberized concrete structures under static and impact load conditions. Experimental Mechanics, 53(3), 377-384. https://doi.org/10.1007/s11340-012-9651-z

British Standard Institution (BSI). (2011). Cement, composition, specifications and conformity criteria for common cements (BS EN 197-1: 2011). London, UK.

British Standards Institution (BSI). (2012). Fly ash for concrete. Definition, specifications and conformity criteria (BS EN 4501:2012). London, UK.

British Standard Institution (BSI). (2016). BSI Standards Publication Methods of testing cement Part 1 (BS EN 196-1: 2016).

Chung, S.-Y., Abd Elrahman, M., Sikora, P., Rucinska, T., Horszczaruk, E., \& Stephan, D. (2017). Evaluation of the effects of crushed and expanded waste glass aggregates on the material properties of lightweight concrete using image-based approaches. Materials, 10(12), 1354. https://doi.org/10.3390/ma10121354

Dong, Q., Huang, B., \& Shu, X. (2013). Rubber modified concrete improved by chemically active coating and silane coupling agent. Construction and Building Materials, 48, 116-123. https://doi.org/10.1016/j.conbuildmat.2013.06.072

Gerges, N. N., Issa, C. A., \& Fawaz, S. A. (2018). Rubber concrete: Mechanical and dynamical properties. Case Studies in Construction Materials, 9, e00184. https://doi.org/10.1016/j.cscm.2018.e00184

German National Standard. (2009). Testing fresh concrete-Part 5. Flow table test (DIN EN 12350-5: 2009). German version EN 12350-5:2009.

Gregorova, V., Ledererova, M., \& Stefunkova, Z. (2017). Investigation of influence of recycled plastics from cable, ethylene vinyl acetate and polystyrene waste on lightweight concrete properties. Procedia Engineering, 195, 127-133. https://doi.org/10.1016/j.proeng.2017.04.534

Hernández-Olivares, F., Barluenga, G., Bollati, M., \& Witoszek, B. (2002). Static and dynamic behaviour of recycled tyre rubberfilled concrete. Cement and Concrete Research, 32(10), 1587-1596. https://doi.org/10.1016/S0008-8846(02)00833-5

Liu, H., Wang, X., Jiao, Y., \& Sha, T. (2016). Experimental investigation of the mechanical and durability properties of crumb rubber concrete. Materials, 9(3), 172. https://doi.org/10.3390/ma9030172

Pichór, W., Kamiński, A., Szołdra, P., \& Frąc, M. (2019). Lightweight cement mortars with granulated foam glass and waste perlite addition. Advances in Civil Engineering, 2019, Article ID 1705490, 9 p. https://doi.org/10.1155/2019/1705490

Ramdani, S., Guettala, A., Benmalek, M. L., \& Aguiar, J. B. (2019). Physical and mechanical performance of concrete made with waste rubber aggregate, glass powder and silica sand powder. Journal of Building Engineering, 21, 302-3011. https://doi.org/10.1016/j.jobe.2018.11.003

Segre, N., \& Joekes, I. (2000). Use of tire rubber particles as addition to cement paste. Cement and Concrete Research, 30(9), 14211425. https://doi.org/10.1016/S0008-8846(00)00373-2

Su, H., Yang, J., Ling, T. C., Ghataora, G. S., \& Dirar, S. (2015). Properties of concrete prepared with waste tyre rubber particles of uniform and varying sizes. Journal of Cleaner Production, 91, 288-296. https://doi.org/10.1016/j.jclepro.2014.12.022

Sugapriya, P., \& Ramkrishnan, R. (2018). Crumb rubber recycling in enhancing damping properties of concrete. In IOP Conference Series: Materials Science and Engineering (vol. 310, conference 1). https://doi:10.1088/1757-899X/310/1/012013

Thomas, B. S., \& Gupta, R. Ch. (2016). Properties of high strength concrete containing scrap tire rubber. Journal of Cleaner Production, 113, 86-92. https://doi.org/10.1016/j.jclepro.2015.11.019

Thomas, B. S., Gupta, R. Ch., \& Panicker, V. J. (2016). Recycling of waste tire rubber as aggregate in concrete: durability related performance. Journal of Cleaner Production, 112(Part 1), 504-513. https://doi.org/10.1016/j.jclepro.2015.08.046 